\title{
Treatment adherence and patients' acceptance of home infusions with adenosine 5'-triphosphate (ATP) in palliative home care
}

\author{
Sandra Beijer • Nicole E. G. Wijckmans • \\ Erik van Rossum • Cor Spreeuwenberg • \\ Ron A. G. Winkens • Lisette Ars • Pieter C. Dagnelie
}

Received: 15 January 2008 / Accepted: 4 September 2008 / Published online: 23 September 2008

(C) The Author(s) 2008. This article is published with open access at Springerlink.com

\begin{abstract}
Goals of work In preterminal cancer patients, provision of palliative care in the patients' own environment is preferred. The aim of the present study was to evaluate patients' and caregivers' treatment adherence and patients' acceptance of home infusions with adenosine 5'-triphosphate (ATP).

Patients and methods Preterminal cancer patients (life expectancy $<6$ months) with mixed tumor types were eligible for the study. Patients received a maximum of eight weekly intravenous $8-10 \mathrm{~h}$ ATP infusions. Evaluation
\end{abstract}

S. Beijer $(\bowtie) \cdot$ N. E. G. Wijckmans $\cdot$ P. C. Dagnelie Department of Epidemiology, NUTRIM, Maastricht University, P.O. Box 616, 6200 MD Maastricht, The Netherlands e-mail: sandra.beijer@epid.unimaas.nl

E. van Rossum $\cdot$ C. Spreeuwenberg

Department of Health Care Studies, Maastricht University,

P.O. Box 616, 6200 MD Maastricht, The Netherlands

E. van Rossum

Center of Expertise on Autonomy and Participation,

University Zuyd,

Heerlen, The Netherlands

R. A. G. Winkens

Department of Integrated Care, University Hospital Maastricht, P.O. Box 5800, 6202 AZ Maastricht, The Netherlands

R. A. G. Winkens

Department of General Practice, Maastricht University,

P.O. Box 616, 6200 MD Maastricht, The Netherlands

L. Ars

Home Care Organization,

Groenekruis Domicura Maastricht and area,

Mockstraat 1, 6226 CA Maastricht, The Netherlands of treatment adherence was based on registration of protocol deviations and patients' acceptance by structured interviews with patients.

Main results Fifty-one patients received a total of 266 intravenous ATP infusions. The infusion protocol was well executed: mean duration $\approx 8.30 \mathrm{~h}$, stepwise achievement of the maximum infusion rate within $30 \mathrm{~min}$ in $65 \%$ of the infusions, and almost no delay in weekly administration. All except one patient were not burdened by the administration of the infusions at home and none of them had felt afraid. The majority of patients found the advantages of the ATP infusions outweighing the disadvantages. However, an important bottleneck in the administration of ATP infusions at home was difficulty in establishing venous access. Conclusion ATP infusions at home are well accepted by patients. Difficulties in establishing venous access might be reduced by composing specialized home infusion teams working both at the day care center and at home or by adopting an alternative route of venous access.

Keywords ATP. Treatment adherence · Home infusion · Palliative care

\section{Introduction}

Over the past 15 to 20 years, a major change in the delivery of health care has occurred. Increasing numbers of patients suffering from different diseases receive intravenous therapy at home including intravenous antibiotics, steroids, biphosphonates, and parenteral nutrition [8-11, 14, 17, 19, 20]. Also in cancer care, home administration of intravenous medication (chemotherapy, opiates) is becoming a widely used alternative to treatment in hospital $[7,14,17]$. Especially 
in terminally ill cancer patients, it is preferred to provide palliative care in their own environment $[18,19]$.

A potential agent in palliative care is adenosine $5^{\prime}$ triphosphate (ATP). A randomized clinical trial in patients with advanced non-small cell lung cancer [3, 4] showed that ATP infusions had marked favorable effects on body weight, muscle strength, fatigue, nutritional intake, quality of life, and survival $[1,3,4]$.

Unfortunately, ATP cannot be given by alternative routes of administration like oral application or hypodermoclysis. In studies published so far, ATP infusions were given in a clinical setting. However, several authors $[2,12,13]$ have reported that continuous application of low-dose ATP is generally safe. Dyspnea, chest discomfort, and the urge to take a deep breath were the most common side effects; all side effects were mild and transient, resolving within minutes after lowering the ATP dose. No symptoms of cardiac ischemia occurred in any of the infusions $[2,5]$. Because of the favorable safety profile of ATP and to diminish the burden on the patients, we decided to administer ATP at the patient's home. The aim of the present study was to evaluate patients' and caregivers' treatment adherence to the ATP infusion protocol and patients' acceptance of ATP infusions at home.

\section{Patients and methods}

\section{Patients}

Patients were recruited through the Departments of Medical Oncology and Pulmonology of five hospitals in the southern half of The Netherlands (located in Maastricht, Eindhoven, Utrecht, and Heerlen) and through 50 general practitioners in the region of Maastricht. Eligible for the study were patients with cytologically or histologically confirmed cancer, for whom medical treatment options were restricted to supportive care, who had a life expectancy $<6$ months, and had a World Health Organization (WHO) performance status 1 or 2. Since the present study was part of a randomized clinical trial aiming to study the effects of ATP on nutritional status and fatigue, eligible patients also had to suffer from at least one of the following complaints: fatigue, anorexia, or weight loss $>5 \%$ over the previous 6 months. Excluded were patients with symptomatic angina pectoris, symptomatic heart failure, or any form of atrioventricular block (assessed by electrocardiogram), life expectancy $<4$ weeks, concurrent palliative chemotherapy, and cognitive dysfunction. After baseline measurements, patients were randomly allocated to ATP or control treatment, using computer-generated random numbers with permutation blocks of four. One hundred patients were randomly assigned to the ATP $(n=51)$ or control $(n=49)$ group. The present report on treatment adherence and patients' acceptance of ATP administration at home is restricted to all 51 patients randomized to ATP treatment. Baseline characteristics of ATP-treated patients are shown in Table 1. The study was approved by the Ethical Committees of all hospitals involved in the study, and all patients signed written informed consent prior to the study. Details of the trial design have been published elsewhere [6].

\section{Treatment protocol}

Over a period of 8 weeks, patients received eight ATP courses of 8-10 h each, at weekly intervals. To prevent side effects, all ATP infusions started beginning at a dose of $20 \mathrm{mcg} / \mathrm{kg} \cdot \mathrm{min}$ and were increased in steps of $10 \mathrm{mcg} / \mathrm{kg}$. min every $10 \mathrm{~min}$ until a maximum dose of $50 \mathrm{mcg} / \mathrm{kg} . \mathrm{min}$, or in case of side effects, until the maximally tolerated dose (MTD) had been reached. Thereafter, ATP was infused at a constant rate. Since initiation of ATP infusions under medical supervision in a clinical setting would facilitate the treatment of possible side effects, the first two ATP infusions were given at the day care center of the participating hospitals. Based on the mild character of the noted side effects during the first two infusions in the first 22 patients, in order to minimize hospitalization of these preterminal patients, an amendment was granted by the Ethical Committee during the study for administering only the first ATP infusion at the day care center. All subsequent infusions were administered at home by experienced, highly qualified, and trained nurses of the infusion team of the regional Home Care Organization or hospital. Eligibility for home infusion therapy was checked using specific criteria (Table 2). Patients and their informal

Table 1 Baseline characteristics of ATP-treated patients $(n=51)$

\begin{tabular}{lll}
\hline & Number & Percent \\
\hline Age (years) & $68.1(45-87)^{\mathrm{b}}$ & \\
Gender & & \\
Male & 35 & 69 \\
Female & 16 & 31 \\
WHO performance score ${ }^{\mathrm{a}}$ & & \\
1 & 33 & 65 \\
2 & 18 & 35 \\
Tumor type & & \\
Lung & 21 & 41 \\
Colon & 8 & 16 \\
Gastrointestinal other & 6 & 12 \\
Prostate & 5 & 10 \\
Other & 11 & 21 \\
\hline
\end{tabular}

${ }^{a}$ WHO 1 -restricted in physically strenuous activity but ambulatory and able to do light work; WHO 2 -ambulatory (not more than $50 \%$ in bed) and capable of self-care but unable to carry out any work ${ }^{\mathrm{b}}$ Mean (range) 
Table 2 Eligibility criteria for home infusion therapy

Appropriate housing situation and sanitary conditions

Telephone or comparable device for external communication

Presence of informal caregiver in the home

Psychological ability of patient and family to cope with the potential stress of home infusions

Motivation of patient and informal care giver for home infusions

Acceptance of responsibility for the home infusions, i.e., to report side effects and/or to stop the infusion in case this would be needed

caregivers were instructed in detail on the infusion procedures and to call the infusion team in case of side effects or any other problems. All participating nurses received special instructions (verbal and written) on how to administer, increase, and end the ATP infusions; what to do in case of side effects; which items had to be checked and reported; and how to instruct the patient and/or informal caregiver.

\section{Data collection and analysis}

Patients' adherence was evaluated by registering the number of patients who stopped with the ATP infusions before the end of the study and the reasons for drop out. Patients' acceptance was investigated by structured interviews after four and eight infusions. Only the latest available evaluation was processed for the present paper. These interviews included questions about burden, duration, frequency, and perceived benefits and disadvantages of the infusions as well as feelings of anxiety during the infusions. Adherence to the treatment protocol was evaluated by standardized registration of the course of the infusions and all protocol deviations. All data were analyzed in a descriptive way using SPSS 13.0 for Windows.

\section{Results}

\section{Patients' adherence to ATP administration}

Of the 51 included patients, $6 \%$ did not start with ATP infusions, $29 \%$ received one to three courses, $18 \%$ four to seven courses, and $47 \%$ completed all eight infusions (Fig. 1). Twelve patients decided to continue ATP administration after completion of the eight regular infusions.

Six patients died during the intervention period. Twentyone patients stopped or did not start with ATP infusions for reasons of deterioration in medical condition $(n=14)$, fear of side effects $(n=4)$, or being unsatisfied with the effect of the $\operatorname{ATP}(n=3)$.
Number of infusions

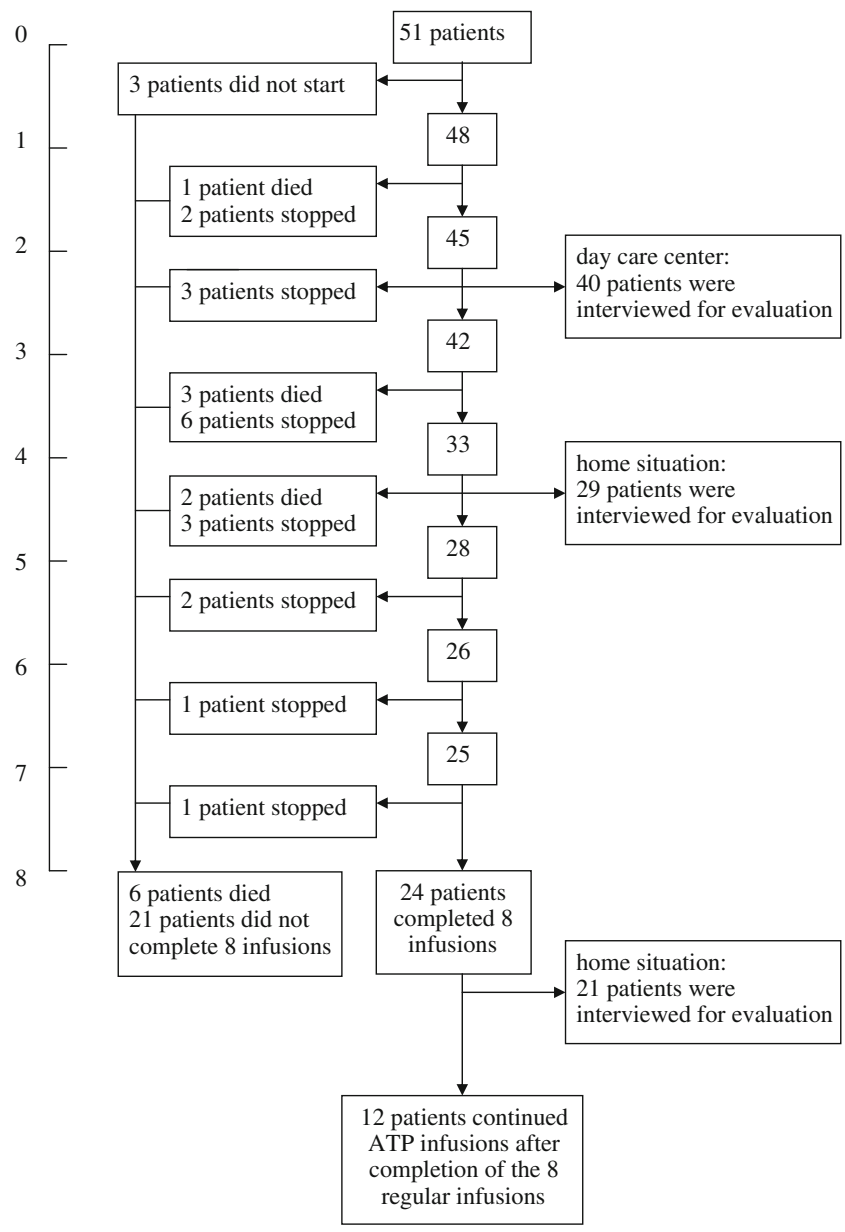

Fig. 1 Flow diagram of the study

Acceptance by patients

Twenty-nine patients (57\% of total) were interviewed about their experiences with ATP infusions at home. Twenty-two patients were not assessable because of death or deterioration in medical condition. All except one patient were not burdened by the home infusions. Patients mentioned that it was more relaxed at home and that it was possible to continue daily activities in one's own environment. The infusion frequency of once a week was evaluated as "good" by 25 patients. The duration of $8-10 \mathrm{~h}$ was experienced as too long by 11 patients, although many patients added that they accepted the infusion duration that was perceived necessary for obtaining maximal results. None of the patients had felt afraid during the home infusions. Twenty-one patients found the advantages of the ATP infusions outweighing the disadvantages. Main disadvantages of home infusions mentioned by patients were problems with establishing venous access, restriction of daily activities by the infusion, and burden for the informal caregiver. 
Protocol adherence

A summary of protocol deviations is given in Table 3. Of the 408 planned ATP infusions, 142 infusions were not administered due to deterioration of medical condition or death.

Of the 266 infusions given, 95 infusions (36\%) were administered at the day care center of the participating hospitals and 171 infusions (64\%) at home. In eight patients, more than two infusions were given at the day care center. Reasons for this were, among other things, fear of side effects or the unavailability of an informal caregiver.

The mean duration of the ATP infusions at home was $8 \mathrm{~h}$ $33 \mathrm{~min}$ (standard deviation (SD) $1 \mathrm{~h} 35 \mathrm{~min}$ ). The mean period to reach the MTD amounted to $27 \mathrm{~min}$ at home. According to the study protocol, nurses were to stay with the patient for $30 \mathrm{~min}$ after reaching the MTD. The total spent time was $\approx 1 \mathrm{~h}$ at the start of each infusion and $\approx 0.5 \mathrm{~h}$ at the end of each infusion. In 22 out of 266 infusions, the home nurse had been called during the infusion and had to visit the patient to solve the problems (side effects, infusion pump alarm, etc.), implicating an additional time investment varying from 30-90 min.

\section{Discussion}

The objective of this study was to evaluate treatment adherence and patients' acceptance of ATP infusions at home in patients with preterminal cancer. As far as we know, this is the first study in which ATP infusions have been systematically administered at home. Results show that the administration of the infusions was largely carried out according to protocol: mean duration $\approx 8.30 \mathrm{~h}$, stepwise achievement of the maximum infusion rate within 30 minutes in $65 \%$ of the infusions, and almost no delay in weekly administration.

However, an important bottleneck in the administration of ATP infusions at home was difficulty in establishing venous access, possibly due to the history of chemotherapy in many patients. As far as we know, little is written about this problem in the literature. In most studies, venous access devices (Port-a-cath, peripherally inserted central catheter (PICC), or peripheral venous cannula) were inserted during hospital stay or at the day care unit and left in place when the patient went home $[8,14,17,20]$. In our study, the peripheral venous cannula had to be inserted at home by the home nurse of the infusion team. Lapostolle et al. [15] reported a study on a total of 671 attempts to obtain peripheral intravenous access in 495 patients in emergency care in out-of-hospital settings. The first attempt was successful in 368 cases (74\%) and unsuccessful in 127 (26\%). Peripheral intravenous access was finally achieved in $99 \%$ of the patients. Improved success rate was reported when attempts were performed by a nurse specialized in emergency care in patients without a particular medical history like chemotherapy, diabetes, or previous multiple hospitalizations. Initial teaching and regular practice significantly increased the success rate [15].

Table 3 Protocol and deviations from protocol

\begin{tabular}{|c|c|c|c|}
\hline & Protocol & \multicolumn{2}{|c|}{ Actual performance of ATP administration } \\
\hline Number of infusions & $\begin{array}{l}408 \text { infusions planned } \\
(8 \text { infusions } \times 51 \text { patients })\end{array}$ & $\begin{array}{l}266 \text { infusions administered } \\
0 \text { infusions } \\
1-3 \text { infusions } \\
4-7 \text { infusions } \\
8 \text { infusions }\end{array}$ & $\begin{array}{l}3 \text { patients }(6 \%) \\
15 \text { patients }(29 \%) \\
9 \text { patients }(18 \%) \\
24 \text { patients }(47 \%)\end{array}$ \\
\hline $\begin{array}{l}\text { Mean duration } \\
\text { of infusions }\end{array}$ & $8-10 \mathrm{~h}$ & $\begin{array}{l}\text { Day care center } \\
\text { At home }\end{array}$ & $\begin{array}{l}8 \text { h } 05 \min \pm 0 \text { h } 49 \min (\text { mean } \pm \text { SD }) \\
8 \text { h } 33 \min \pm 1 \text { h } 35 \text { min }\end{array}$ \\
\hline Run in period & $30-45 \mathrm{~min}$ & $\begin{array}{l}<30 \mathrm{~min} \\
30-45 \mathrm{~min} \\
>45 \mathrm{~min} \\
\text { Unknown }\end{array}$ & $\begin{array}{l}172 \text { infusions }(65 \%) \\
55 \text { infusions }(21 \%) \\
27 \text { infusions }(10 \%) \\
12 \text { infusions }(5 \%)\end{array}$ \\
\hline Frequency & Once per week & $\begin{array}{l}\text { Once per week } \\
\text { Delayed for } 14 \text { days }\end{array}$ & $\begin{array}{l}263 \text { infusions } \\
3 \text { infusions }\end{array}$ \\
\hline $\begin{array}{l}\text { Day care center: } \\
95 \text { infusions }(36 \%)\end{array}$ & First two infusions & $\begin{array}{l}\text { First infusion } \\
\text { First two infusions }\end{array}$ & $\begin{array}{l}25 \\
15\end{array}$ \\
\hline $\begin{array}{l}\text { At home: } \\
171 \text { infusions }(64 \%)\end{array}$ & & More than two infusions & 8 \\
\hline $\begin{array}{l}\text { Establishing venous access } \\
\text { at home }\end{array}$ & Home infusion nurses & $\begin{array}{l}\text { Home infusion nurses } \\
\text { Day care center } \\
\text { Ambulance personnel } \\
\text { Hospital nurse at home }\end{array}$ & $\begin{array}{l}137 \text { infusions }(80 \%) \\
25 \text { infusions }(15 \%) \\
6 \text { infusions }(4 \%) \\
3 \text { infusions }(2 \%)\end{array}$ \\
\hline
\end{tabular}


In our study, one of our participating centers solved the problem of difficulties in establishing venous access by a transmural infusion team composed of trained infusion nurses working both at the hospital and in the home situation, thus providing regular practice in inserting infusion needles. Another solution would be to choose an alternative route of venous access. In the present study, a PICC was successfully inserted in one patient.

Our finding that most patients and informal caregivers preferred home infusions is in accordance with other studies. A study comparing hospital and home antibiotic treatment for cellulitis showed that home care is the preferred treatment choice by patients, particularly for those patients who have experienced community care before [9]. In patients with colon cancer receiving chemotherapy, global patient satisfaction with health care was greater in patients receiving home chemotherapy than in patients receiving outpatient treatment [7]. In a study in patients with Fabry disease [16], most patients also preferred treatment at home.

A considerable proportion of patients $(38 \%)$ perceived the duration of the infusions at home as too long. Further investigations are warranted to explore other treatment schedules. Technological development may allow smaller, more mobile, and less noisy infusion pumps, contributing to patient comfort.

No feelings of anxiety were reported by the patients in the present study. Zimran et al. [20] also showed no feelings of fear or anxiety associated with infusion treatment at home. In contrast, study patients participating in a self-administration program in which they had to handle the venous access device themselves [14] did show feelings of uncertainty and anxiety. With regard to the first infusion, our study indicates that patients felt safe when this infusion was administered at the day care center.

This evaluation study has some limitations. Inherent to the study population of preterminal cancer patients is the relatively small proportion of patients who completed all eight infusions. This may have led to selection bias since patients with the worst condition will drop out first, restricting the evaluation to patients with fewer problems and easier-to-administer infusions. Furthermore, for logistic reasons, data for the present study had to be collected by the same researcher who was involved in patient instruction and organization of the infusion protocol. Even though great care was taken to allow patients and caregivers to freely express their opinion and feelings, the possibility of biased information by socially desired answers cannot be completely disregarded.

Despite these limitations, we conclude that patients' and caregivers' adherence to the ATP infusion protocol is high and that ATP infusions at home are well accepted by patients. Possibilities to increase the comfort for the patient would be to perform the infusion during the night. Difficulties in establishing venous access might be reduced by composing specialized home infusion teams working both at the day care center and at home or by adopting an alternative route of venous access.

Acknowledgements This study was supported by a grant within the programme "Palliative Care in the Terminal Phase" of the Netherlands Organisation for Health Research and Development (ZonMw) and by the 'Stichting Nationaal Fonds Tegen Kanker' (Foundation National Fund against Cancer), The Netherlands. The authors would like to thank Nicole Wijckmans for assistance with measurements and logistics.

Open Access This article is distributed under the terms of the Creative Commons Attribution Noncommercial License which permits any noncommercial use, distribution, and reproduction in any medium, provided the original author(s) and source are credited.

\section{References}

1. Agteresch HJ, Burgers SA, van der Gaast A, Wilson JH, Dagnelie PC (2003) Randomized clinical trial of adenosine 5 '-triphosphate on tumor growth and survival in advanced lung cancer patients. Anticancer Drugs 14:639-644 doi:10.1097/00001813200309000-00009

2. Agteresch HJ, Dagnelie PC, Rietveld T, van den Berg JW, Danser AH, Wilson JH (2000) Pharmacokinetics of intravenous ATP in cancer patients. Eur J Clin Pharmacol 56:49-55 doi:10.1007/ s002280050719

3. Agteresch HJ, Dagnelie PC, van Der Gaast A, Stijnen T, Wilson JH (2000) Randomized clinical trial of adenosine 5'-triphosphate in patients with advanced non-small-cell lung cancer. J Natl Cancer Inst 92:321-328 doi:10.1093/jnci/92.4.321

4. Agteresch HJ, Rietveld T, Kerkhofs LG, van den Berg JW, Wilson JH, Dagnelie PC (2002) Beneficial effects of adenosine triphosphate on nutritional status in advanced lung cancer patients: a randomized clinical trial. J Clin Oncol 20:371-378 doi:10.1200/ JCO.20.2.371

5. Beijer S, Gielisse EA, Hupperets PS, van den Borne BE, van den Beuken-van Everdingen M, Nijziel MR et al (2007) Intravenous ATP infusions can be safely administered in the home setting: a study in pre-terminal cancer patients. Invest New Drugs 25:571579 doi:10.1007/s10637-007-9076-1

6. Beijer S, van Rossum E, Hupperets PS, Spreeuwenberg C, van den Beuken M, Winkens RA et al (2007) Application of adenosine 5 '-triphosphate (ATP) infusions in palliative home care: design of a randomized clinical trial. BMC Public Health 7:4 doi:10.1186/1471-2458-7-4

7. Borras JM, Sanchez-Hernandez A, Navarro M, Martinez M, Mendez E, Ponton JL et al (2001) Compliance, satisfaction, and quality of life of patients with colorectal cancer receiving home chemotherapy or outpatient treatment: a randomised controlled trial. BMJ 322:826-830 doi:10.1136/bmj.322.7290.826

8. Chataway J, Porter B, Riazi A, Heaney D, Watt H, Hobart J et al (2006) Home versus outpatient administration of intravenous steroids for multiple-sclerosis relapses: a randomised controlled trial. Lancet Neurol 5:565-571 doi:10.1016/S1474-4422(06)70450-1

9. Corwin P, Toop L, McGeoch G, Than M, Wynn-Thomas S, Wells $\mathrm{JE}$ et al (2005) Randomised controlled trial of intravenous 
antibiotic treatment for cellulitis at home compared with hospital. BMJ 330:129-134 doi:10.1136/bmj.38309.447975.EB

10. Esmond G, Butler M, McCormack AM (2006) Comparison of hospital and home intravenous antibiotic therapy in adults with cystic fibrosis. J Clin Nurs 15:52-60 doi:10.1111/j.13652702.2005.01236.x

11. Gorski LA (2004) Central venous access device outcomes in a homecare agency: a 7-year study. J Infus Nurs 27:104-111 doi:10.1097/00129804-200403000-00006

12. Haskell CM, Mendoza E, Pisters KM, Fossella FV, Figlin RA (1998) Phase II study of intravenous adenosine 5'-triphosphate in patients with previously untreated stage IIIB and stage IV nonsmall cell lung cancer. Invest New Drugs 16:81-85 doi:10.1023/ A:1006018610986

13. Haskell CM, Wong M, Williams A, Lee LY (1996) Phase I trial of extracellular adenosine 5 -triphosphate in patients with advanced cancer. Med Pediatr Oncol 27:165-173 doi:10.1002/(SICI)1096911X(199609)27:3<165::AID-MPO6>3.0.CO;2-C

14. Johansson E, Langius-Eklof A, Engervall P, Wredling R (2005) Patients' experience of ambulatory self-administration of pamidronate in multiple myeloma. Cancer Nurs 28:158-165 doi:10.1097/ 00002820-200503000-00011
15. Lapostolle F, Catineau J, Garrigue B, Monmarteau V, Houssaye T, Vecci I et al (2007) Prospective evaluation of peripheral venous access difficulty in emergency care. Intensive Care Med 33 (8):1452-1457 doi:10.1007/s00134-007-0634-y

16. Linthorst GE, Vedder AC, Ormel EE, Aerts JM, Hollak CE (2006) Home treatment for Fabry disease: practice guidelines based on 3 years experience in The Netherlands. Nephrol Dial Transplant 21:355-360 doi:10.1093/ndt/gfi221

17. Payne SA (1992) A study of quality of life in cancer patients receiving palliative chemotherapy. Soc Sci Med 35:1505-1509 doi:10.1016/0277-9536(92)90053-S

18. Peters L, Sellick K (2006) Quality of life of cancer patients receiving inpatient and home-based palliative care. J Adv Nurs 53:524-533 doi:10.1111/j.1365-2648.2006.03754.x

19. Smeets PM, Beusmans GH, Weber WE (1999) Prospective study of home morphine infusion in 62 terminally ill patients. J Pain Symptom Manage 18:390-400 doi:10.1016/S0885-3924(99) 00105-0

20. Zimran A, Hollak CE, Abrahamov A, van Oers MH, Kelly M, Beutler E (1993) Home treatment with intravenous enzyme replacement therapy for Gaucher disease: an international collaborative study of 33 patients. Blood 82:1107-1109 